\title{
Impact of Date Palm Seed Size on Biogas Production from Date Seeds/Wastewater Treatment Sludge Mixtures
}

\author{
W. Radeef ${ }^{a, *}$, A. Shanableh ${ }^{a, b}$, T. Merabtene $^{a}$ \\ ${ }^{a}$ Department of Civil and Environmental Engineering, University of Sharjah, Sharjah, United Arab Emirates \\ ${ }^{b}$ Research Institute of Sciences and Engineering, University of Sharjah, PO Box 2727, Sharjah, United Arab Emirates
}

\begin{abstract}
Biogas in the form of methane can be produced from wastewater treatment sludge mixed with a variety of biodegradable organic feedstocks through anaerobic digestion. In this study, biogas was produced from date palm seeds, which are locally available, and wastewater treatment sludge mixtures. The objective of the study was to assess the effect of date palm seed additives with different sizes on biogas production from the mixtures. In the study, two locally available types of date seeds, Khalas and Khudari, were anaerobically co-digested with wastewater treatment sludge in $50 \mathrm{~mL}$ serum bottles under mesophilic conditions. Date seeds with three different sizes; $1.18-3.75 \mathrm{~mm}, 0.6-1.18 \mathrm{~mm}$; and $0.425-0.6 \mathrm{~mm}$, were added to the sludge at date seeds to sludge total solids (TS) weight ratios of $0 \%, 2.5 \%, 5 \%, 7.5 \%$, and $10 \%$. The experimental results confirmed that the addition of date seeds significantly enhanced biogas production up to $20 \%$ to $30 \%$. The results indicated that the date seed size slightly affected biogas production, with the order of cumulative biogas production and biogas production rates, expressed in terms of date seed sizes, being as follows: $0.425-0.6 \mathrm{~mm}>0.6-$ $1.18 \mathrm{~mm}>1.18-3.75 \mathrm{~mm}$. However, the results showed no major difference in biogas production between the two different date seed types.
\end{abstract}

Keywords: Khalas Date Seed, Khudari Date Seed, Wastewater Sludge, Biogas Production, Methane Production, Biofuel

\section{Introduction}

Biogas production from organic waste products is a favorable option because it combines both energy recovery and waste management [1]. Biogas can be produced from locally available organic feedstocks through anaerobic digestion. Locally available waste products for biogas production include: organic solids waste; wastewater treatment sludge; and date palm wastes. Large quantities of wastewater sludge are produced from a number of wastewater treatment plants distributed in the urban areas of the United Arab Emirates (UAE). The population of date palm trees in the UAE continues to increase and in 2011, the UAE was the fourth date fruit producing country in the world with annual production of 900,000 tons [2].
Anaerobic digestion is a biological method that can be used to stabilize industrial and domestic organic wastes in order to control wastes and produce biogas. The main components of produced biogas are carbon dioxide and methane, which can be used in power gas engines [3]. Anaerobic digestion systems are generally slow and suffer from operation stability issues [4] and researchers continue to search for methods to increase and speed up anaerobic biogas production. Date palms are scientifically called Phoenix Dactylifera. The date palm fruit has an oval shape with one to three inches long. It has a large seed in the center of the fruit which makes about 10 percent of the fruit weight. The color of the fruit changes from green to orange, yellow and finally dark brown when the fruit is fully mature. Date palm seeds are rich in biodegradable organic materials, including: protein (5-5.5\%); carbohydrates (81-83\%); and lipids (10-12\%) [5].

${ }^{*}$ Corresponding author. Tel.: +97165050934

Fax: +97165585173; E-mail: wradeef@sharjah.ac.ae

(C) 2016 International Association for Sharing Knowledge and Sustainability

DOI: 10.5383/ijtee.13.01.001 
Date seeds can be used for a variety of purposes, including biofuels production. Researchers [6,7] used date seeds to produce biodiesel with favorable characteristics as a fuel. Only one study was found on the use of date seeds as additives for biogas production [8]. Al-Turky [8] investigated the use of date pits meal as a source for biogas production when mixed with cattle feces by preparing four different mixtures; mixture 1 (100\% cattle feces), mixture 2 (90\% cattle feces and $10 \%$ date pits), mixture 3 ( $80 \%$ cattle feces and $20 \%$ date pits) and mixture 4 (70\% cattle feces and 30\% date pits). The researchers found that the mixture with $90 \%$ cattle feces and $10 \%$ date pits produced the maximum biogas. When the date pits ratio was increased above $10 \%$, biogas production declined. On the other hand, no studies were found to report the effect of the size of date seed additives on biogas production from mixtures of date palm seeds and wastewater sludge.

In this study, wastewater treatment sludge and two types of date palm seeds with three different sizes were co-digested to produce biogas. The main objective of the study was to assess the effect of date palm seed additives with different sizes on biogas production under mesophilic anaerobic digestion conditions.

\section{Materials and Methods}

Primary wastewater treatment sludge was delivered in 40-L containers from Dubai Wastewater Treatment Plant (WWTP) to the University of Sharjah Environmental Engineering Laboratory. The Dubai WWTP serves the entire city of Dubai by receiving the sewage flows from both the principal pumping stations and from the sewage tankers that bring the sewage flow from the areas that have no sewage systems. The total solid (TS) of the primary sludge was modified to $2 \%$ and stored in a freezer in small containers until needed. The volatile solids (VS) after TS adjustment reached $1.64 \%$. The data in Table 1 summarize the characteristics of the sludge.

Table 1. Primary sludge characteristics

\begin{tabular}{lc}
\hline Parameter & Value \\
\hline $\mathrm{pH}$ & 7.3 \\
$\mathrm{TS}(\%)$ & 2.01 \\
$\mathrm{VS}(\%)$ & 1.64 \\
$\mathrm{SCOD}(\mathrm{mg} / \mathrm{L})$ & 1425 \\
$\mathrm{~N}^{\mathrm{N} H} \mathrm{H}_{3}(\mathrm{mg} / \mathrm{L})$ & 160 \\
$\mathrm{P}-\mathrm{PO}_{4}(\mathrm{mg} / \mathrm{L})$ & 39.5 \\
\hline
\end{tabular}

Locally known Khalas and Khudari date seeds were prepared by isolating the date seed from the date fruit. The seeds were then washed to remove any remains of date flesh. The date seeds used in the study are shown in Figure 1.

After washing, the date seeds were dried in the oven 24 hours and their sizes adjusted through crushing, grinding and sieving. The following three date seed sizes were prepared for each of the two seed types: $1.18-3.75 \mathrm{~mm}, 0.6-1.18 \mathrm{~mm}$; and 0.425 $-0.6 \mathrm{~mm}$, as shown in Figure 2.

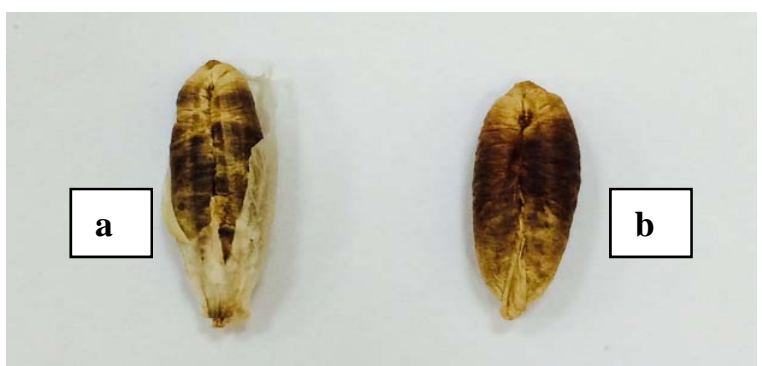

Figure 1: Types of date palm seeds used in the study: (a) Khalas; and (b) Khudari.

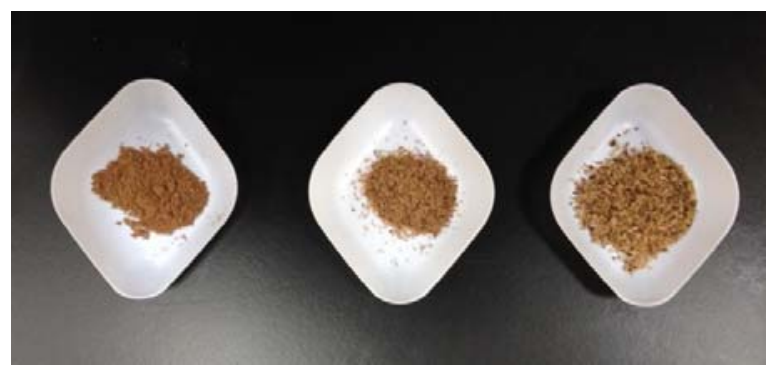

Figure 2: Samples of Khalas date seed with sizes adjusted in the ranges of $0.425-0.6 \mathrm{~mm}, 0.6-1.18 \mathrm{~mm}$, and $1.18-3.75 \mathrm{~mm}$

The composition of the date seeds is summarized in Table 2 . The protein content in Khalas date seeds (7.61\%) was more than in Kudari date seed (5.1\%). While the fat content in Khudari date seeds $(9.7 \%)$ was more than in Khalas date seed (8.75\%).

Table 2. Composition of Khalas and Khudari date seeds

\begin{tabular}{lcc}
\hline Parameter & $\begin{array}{c}\text { Khalas Date Seed } \\
\mathbf{( \% )}\end{array}$ & $\begin{array}{c}\text { Khudari Date Seed } \\
\mathbf{( \% )}\end{array}$ \\
\hline Protein & 7.61 & 5.1 \\
Fats & 8.75 & 9.7 \\
Carbohydrates & 82.54 & 84.17 \\
Fixed Ash Content & 1.1 & 1.03 \\
Volatile Content & 98.9 & 98.97 \\
\hline
\end{tabular}

Mixtures of date seeds and wastewater sludge were prepared by mixing $30 \mathrm{~mL}$ of wastewater sludge with different quantities of date seeds. Five different date seed/sludge total solids (TS) weight ratios were prepared: $0 \%, 2.5 \%, 5 \%, 7.5 \%$ and $10 \%$. The mixtures were placed in $50 \mathrm{ml}$ serum bottles and capped with rubber stoppers and aluminum sealing rings, as shown in Figure 3. The bottles were incubated in an oven at $35^{\circ} \mathrm{C}$ and total and methane biogas production from the different bottles were measured on a weekly basis for 14 weeks. Total biogas was measured through displacing an acidic water solution in an inverted capped long bottle with an outlet. The collected biogas was then passed through a second inverted displacement bottle containing $\mathrm{NaOH}$ solution to absorb $\mathrm{CO}_{2}$ from the biogas, as shown in Figure 4. 


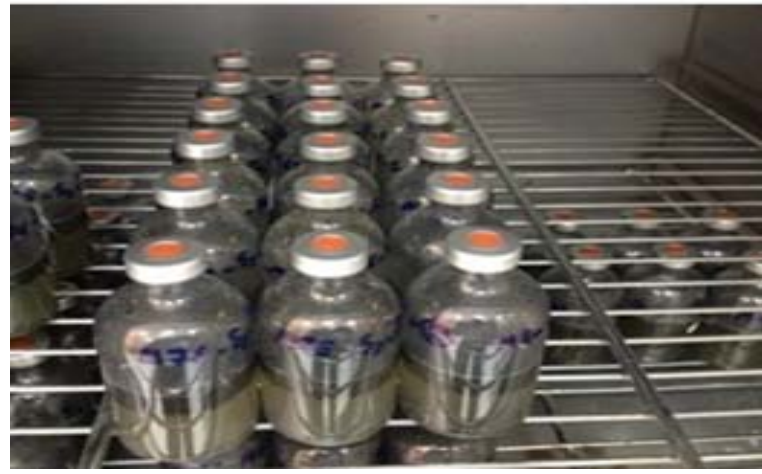

Figure 3: Samples of Date Seeds and Wastewater Sludge

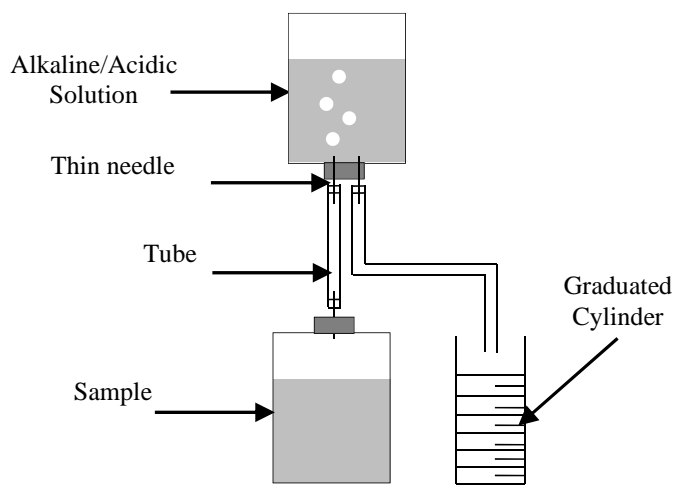

Figure 4: Volumetric total biogas and methane measurement by liquid displacement

The initial and final TS and VS for the digested samples were also measured to determine the extent of digestion. Duplicate samples were used in all experiments and the reported results are means.

\section{Results and Discussion}

Biogas produced by the different date seed/sludge mixtures of both date seed types, Khalas and Khudari, was measured on a weekly basis and recorded. The cumulative biogas production results for the samples containing $2.5 \%, 5 \%, 7.5 \%$ and $10 \%$ date seeds/sludge mixtures are shown in Figures 5 to 12.

The results in Figures 5 to 12 consistently show that biogas production from Khalas and Khudari date seed types and sludge mixtures followed similar trends and produced nearly equal cumulative biogas quantities. Furthermore, the cumulative biogas results were highest from the mixtures containing the smallest date seeds size and lowest from the samples containing the largest date seed size, however the differences between the largest and smallest results were not high.

The results show significant enhancement of biogas production from the sludge due to the addition of date seeds. For example, adding $10 \%$ date seeds resulted in approximately $20 \%$ to $30 \%$ increase in cumulative biogas production. Such enhancement is significant and suggests that small quantities of date seeds can significantly enhance biogas production from sludge.

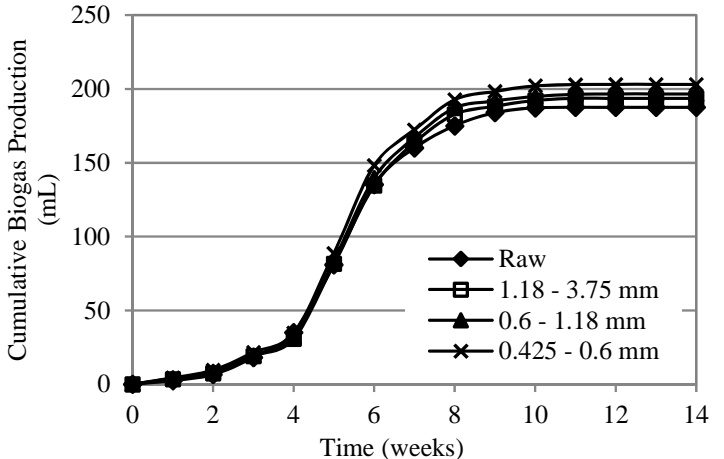

Figure 5: Biogas production from the $2.5 \%$ Khalas date seed/sludge mixtures

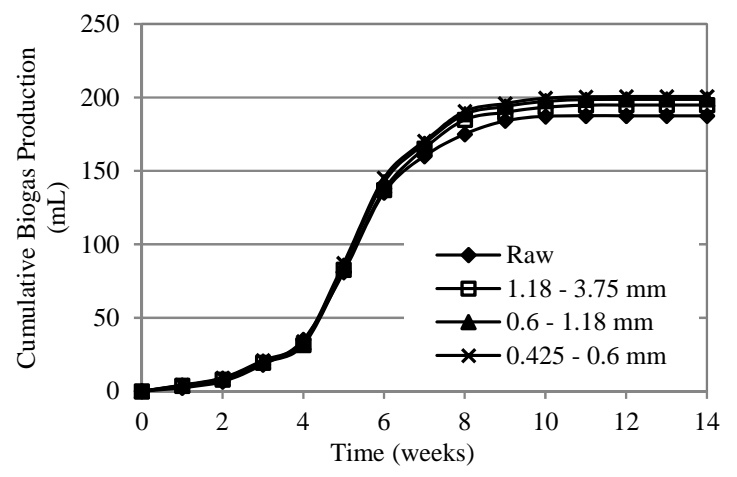

Figure 6: Biogas production from the $2.5 \%$ Khudari date seed/sludge mixtures

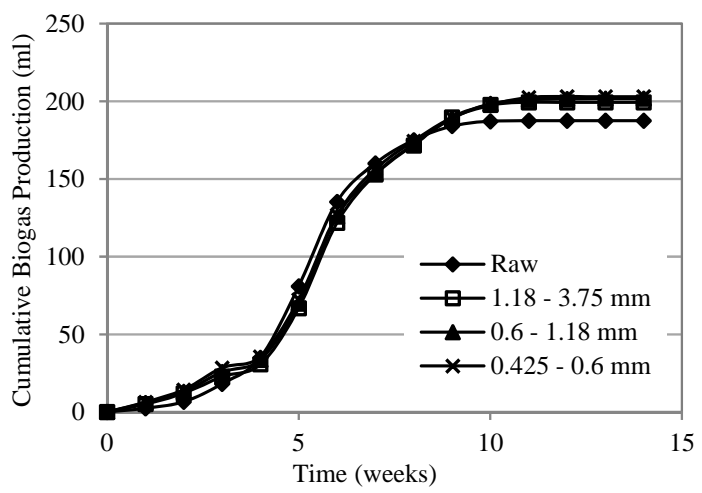

Figure 7: Cumulative Biogas Production from Different Sizes of 5\% Khalas Date Seed/Sludge Mixtures

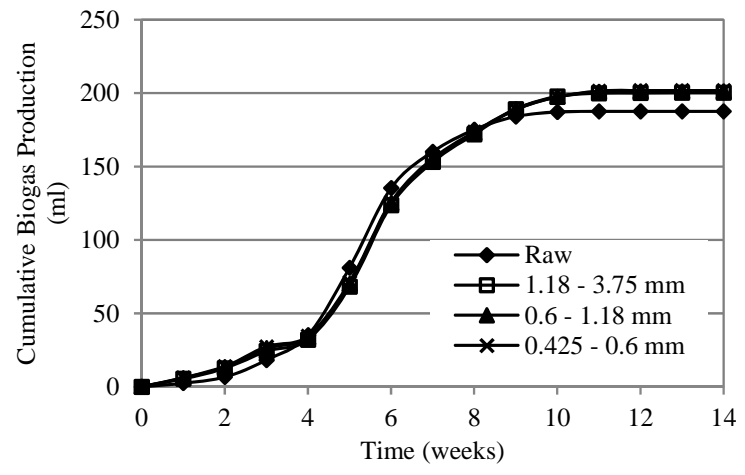

Figure 8: Cumulative Biogas Production from Different Sizes of 5\% Khudari Date Seed/Sludge 


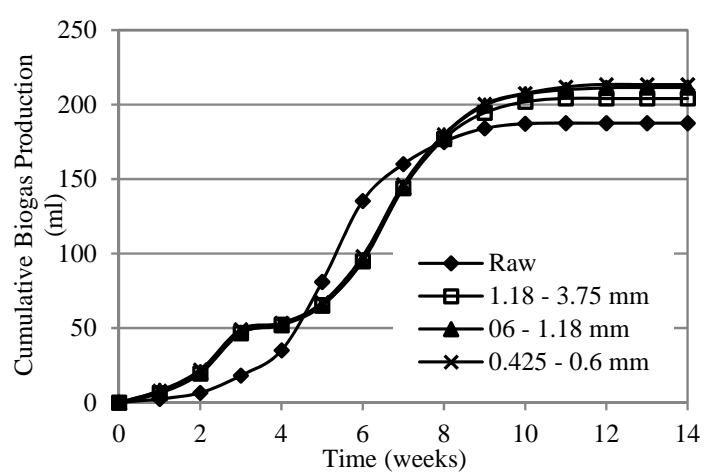

Figure 9: Cumulative Biogas Production from Different Sizes of 7.5\% Khalas Date Seed/Sludge Mixtures

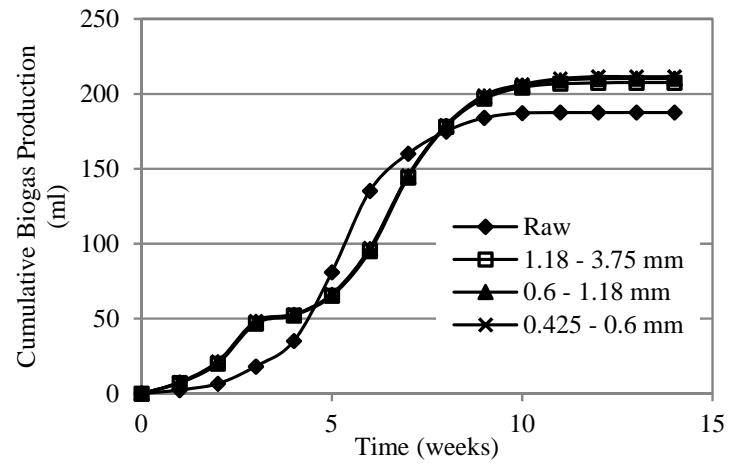

Figure 10: Cumulative biogas production from different sizes of $7.5 \%$ khudari date seed/sludge mixtures

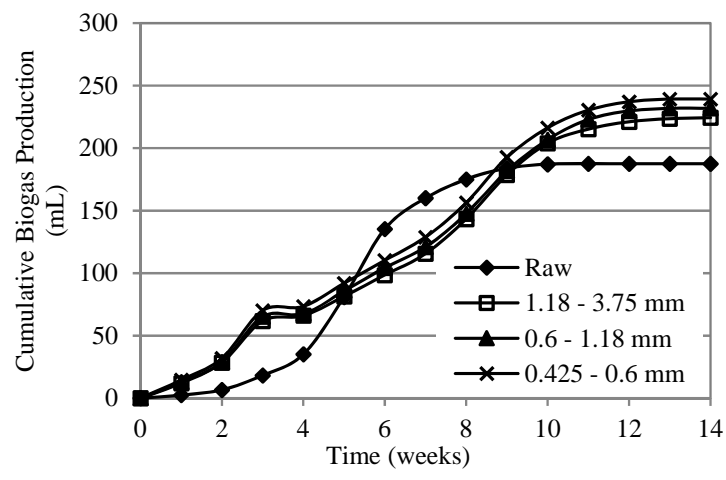

Figure 11: Biogas production from the $10 \%$ Khalas date seed/sludge mixtures

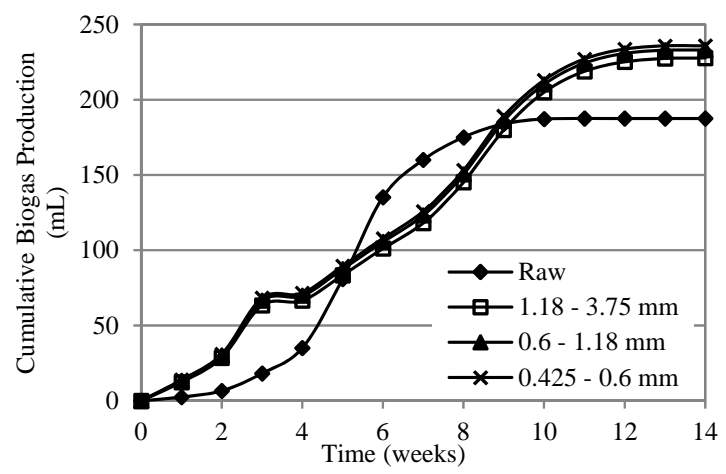

Figure 12: Biogas production from the $10 \%$ Khudari date seed/sludge mixtures
The experimental results in Figures 5-12 are summarized in Figures 13 and 14 . Clearly, cumulative biogas production increased as the ratio of date seeds in the date seed/sludge mixtures increased. The order of biogas production after 14 weeks of incubation in terms of date seeds ratio in the seed/sludge mixtures was as follows: $10 \%>7.5 \%>5 \%>2.5 \%$ $>0 \%$. The same order also applies to the rate of biogas production.

The data in Figures 13 and 14 also show that the date seed size slightly affected biogas production from the three studied date seed sizes. Biogas production was in the following order, in terms of the three date seed sizes: $0.425-0.6 \mathrm{~mm}>0.6-1.18$ $\mathrm{mm}>1.18-3.75 \mathrm{~mm}$. Date seeds are tough to crush and grind and the fact that the size did not significantly affect biogas production within the studied size ranges can reduce the cost and effort of modifying the date seed sizes for biogas production.

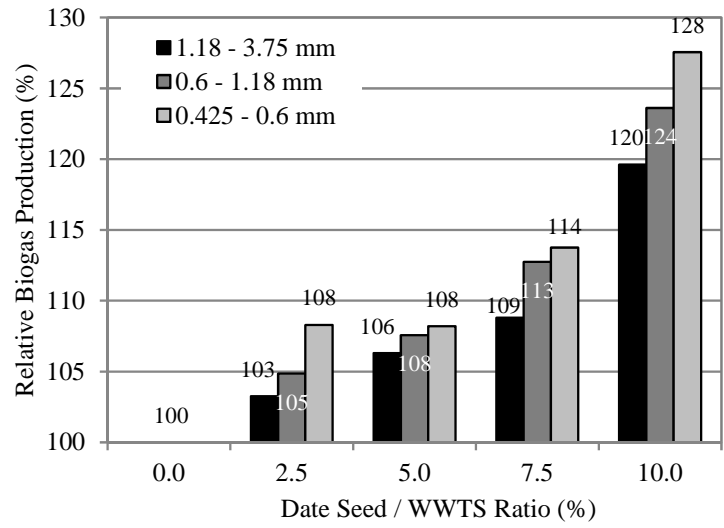

Figure 13: Relative biogas production after fourteen weeks from different khalas date seed sizes

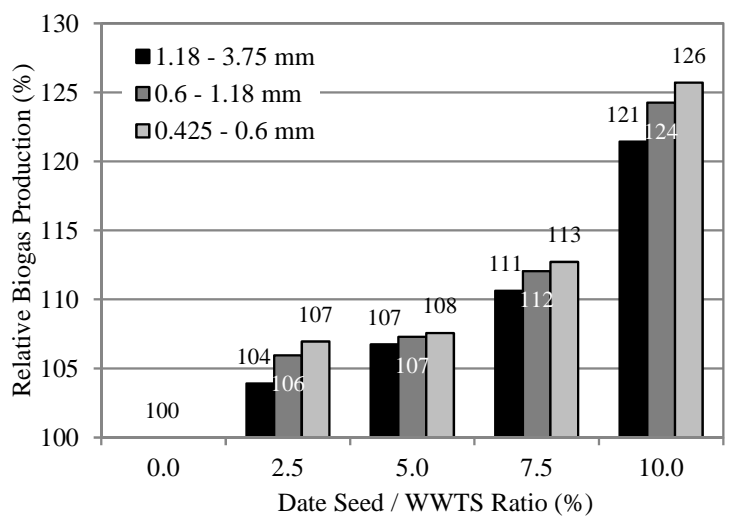

Figure 14: Relative biogas production after fourteen weeks from different khudari date seed sizes

The data in Figures 15 and 16 degree of sludge digestion, expressed in terms of VS removal, achieved during biogas production. The TS and VS removal percentages were significant (34-42\% for TS and $44-52 \%$ for VS) and were almost the same for the two different date seed types and for the three seed sizes. The VS digestion results are consistent with the biogas production results. The order of TS and VS removal percentages after 14 weeks of incubation, in terms of date seeds ratio in the seed/sludge mixtures, was in the order: $10 \%>7.5$ $\%>5 \%>40 \%>2.5 \%>0 \%$. 
Radeef et al. / Int. J. of Thermal \& Environmental Engineering, 13 (2016) 1-6

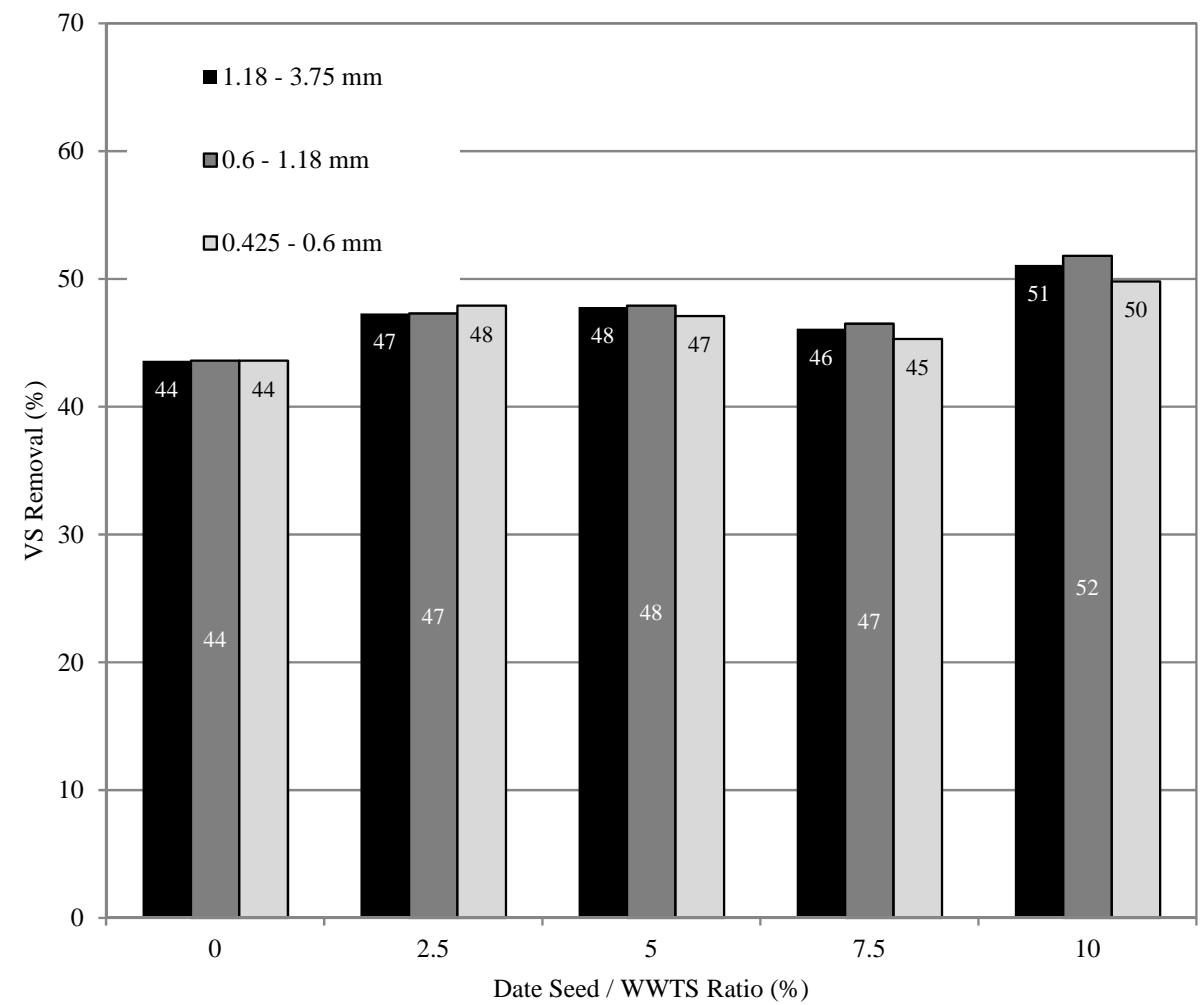

Figure 15: Volatile solids (VS) removal for Khalas date seed/sludge samples

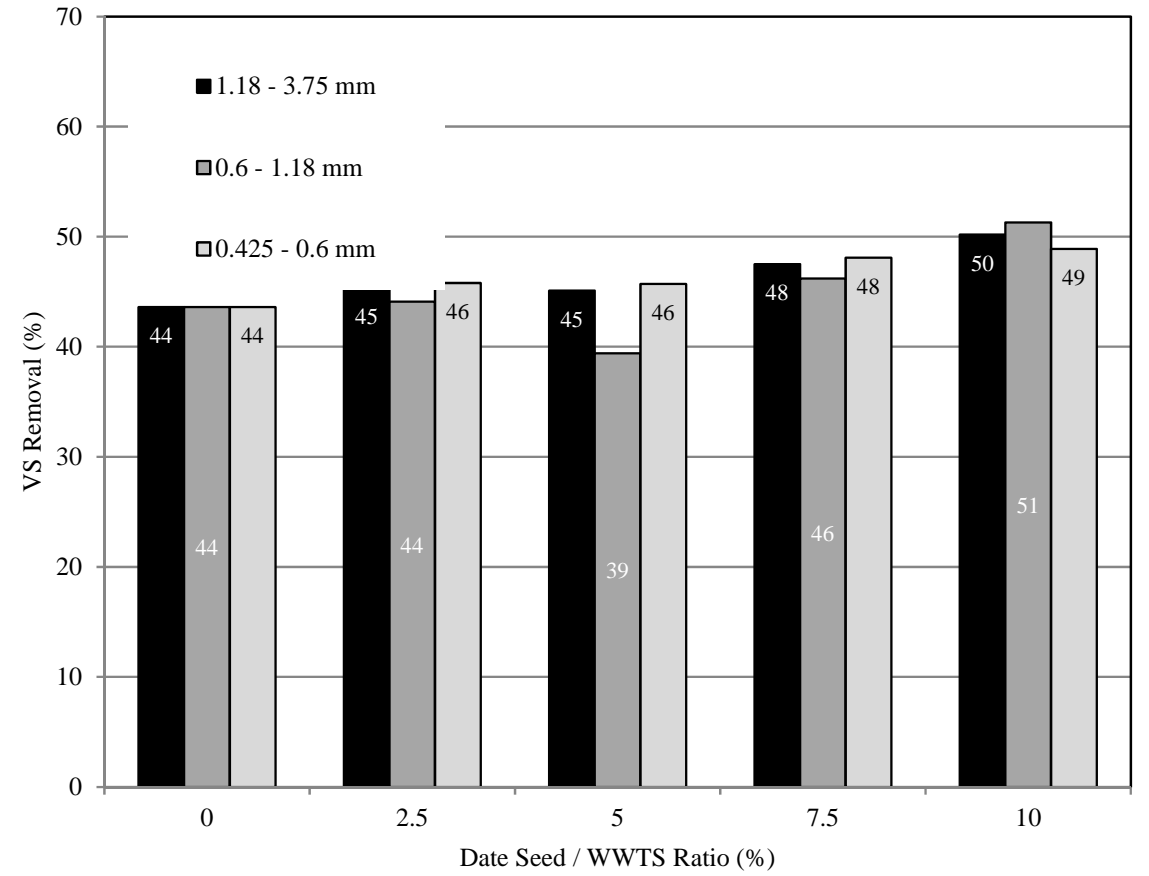

Figure 16: Volatile solids (VS) removal for Khudari date seed/sludge samples 


\section{Conclusion}

Biogas production after 14 weeks of incubation increased as the date seed ratio in the date seed/sludge samples increased for the three different date seed sizes for both Khalas and Khudari date seed types. Furthermore, biogas production from Khalas and Khudari date seeds/sludge mixtures followed similar trends and resulted in nearly equal biogas production results. The maximum production of biogas was from the samples containing $10 \%$ date seeds and the minimum was from samples containing $0 \%$ date seed. The addition of date seeds significantly increased biogas production from the sludge by up to $20-30 \%$ in the samples containing $10 \%$ date seeds. The results indicated that the date seed size in the date seeds/sludge mixtures slightly affected biogas production, with the order of biogas production, expressed in terms of date seed sizes, being as follows: $0.425-0.6 \mathrm{~mm}>0.6-1.18 \mathrm{~mm}>1.18-3.75 \mathrm{~mm}$. The same order also applies to the rate of biogas production during the digestion period.

\section{References}

[1] Y. Kalogo, and H. Monteith, Energy and Resource Recovery from Sludge, Global Water Research Coalition, 2008

[2] United Nation Food and Agriculture Organization, Date Fruit Producing Countries, 2011.
[3] K. Bothi, Characterization of Biogas from Anaerobically Digested Dairy Waste for Energy Use, Cornell University Library, 2007.

[4] M. Dupla, T. Conte, J. Bouview, N. Bernet and J. Steyer, Dynamic evaluation of a fixed bed anaerobicdigestion process in response to organic overloads and toxicant shock loads, Water Science Technology, 2004; 1: 61-68.

[5] S. Besbes, C. Blecker, C. Deroanne, G. Lognay, N. Drira, and H. Attia, Quality Characteristics and Oxidative Stability of Date Seed Oil During Storage, Food Sci. Tech. Int., 2004; 5: 333-338.

[6] M. Amani, M. Davoudi, K. Tahvildari, S. Nabavi and M. Davoudi, Biodiesel production from Phoenix dactylifera as a new feedstock, Industrial Crops and Products, 2013; 40-43.

[7] N. Adam and A. Shanableh, Comparison of Biodiesel Production from a Variety of Feedstocks, Proceedings of the Third International Conference on Water, Energy and Environment (ICWEE), 2015; 362-368.

[8] A. Al-Turky, Y. El-Hadidi and S. Al-Yahya, Utilization of Date Pits As A Potential Source of Biogas and Organic Fertilizer, Agriculture and Environment, 2004;2: 369-374. 